\title{
Marine Drive System Regulation
}

\author{
A. Abdul-Ameer \\ The British University in Dubai, UAE
}

Copyright $(2016$ by authors, all rights reserved. Authors agree that this article remains permanently open access under the terms of the Creative Commons Attribution License 4.0 International License

\begin{abstract}
A single shaft dual turbine drive, for a marine propulsion system, is considered. Distributed-lumped analysis is used in the dynamic response prediction. This enables the relatively concentrated assemblies to be included as lumped, point-wise representations. The propulsion shaft is incorporated as a dispersed inertia and stiffness model. Multivariable, least effort regulation is employed to achieve the control required. The performance of the closed-loop system following reference input and load disturbance changes is evaluated and the drive shaft speed and twist angle response transients are computed.
\end{abstract}

Keywords Marine, Drive, Propulsion, System, Control

\section{Background/Objectives and Goals}

Low and high power engines are often used, for marine system propulsion, to accommodate widely varying load conditions whilst minimizing energy dissipation, cost expenditure and emissions. A variety of applications including hybrid internal combustion/electric motor drives, cruise and manoeuvring gas turbine propulsion, and diesel-electric power transmissions may be configured in this way.

Often a single prime mover is used to obtain the required driving torque, with some form of automatic transfer to the low or high power unit following load changes. As a consequence, during high speed operations the high power prime mover provides the whole of the propulsion with the remaining unit idling, or passively motoring on the drive shaft.

In principle, both units could be used to provide the maximum torque requirement in these applications. However, the difficult issue of load sharing between the two prime movers must then be addressed.

This consideration is complicated owing to the changing load demands on the system which prevail throughout operational duty cycles. The use of epicyclic gearing and/or power electronics may be used to adjust dynamic loading imbalances. However, these are costly solutions which also attract substantial increases in complexity, mass/inertia and maintenance costs, as significant penalties.

An alternative approach would be to treat the tandem, power transmission design problem as a directly coupled drive with the use of multivariable feedback, as in [1], to enforce the required speed/torque and shaft twist regulation.

An appropriate control strategy here would be to simultaneously regulate the transmission shaft speed and twist angle-outputs, with both engines/motors supplying power. This would lead to both drive units operating in concert, in accordance with the required loading and speed changes, without the use of complicated electronic switching or mechanical gearing.

As part of the design, the employment of an accurate drive shaft model for the propulsion system under consideration is necessary. Essentially, the spatial dispersion of this element will be included in the modelling and regulator design exercise, as in [2].

The shaft forward and stern end, shaft twist angle difference, required in the feedback regulation system, will be provided by strain gauge measurements with electrical signal transmission, via shaft mounted slip rings. Speed transducers and integrators will be used for this purpose, as shown herein.

Equally, to ensure cost-effective, efficient implementation a least effort multivariable design strategy will be adopted. This procedure uses only passive control elements whilst minimising the generation of heat, wear and operating costs providing thereby the efficient regulation required, for successful implementation.

In the marine applications included in this submission are particularly important. Effectively, the propulsion system proposed would allow single and/or dual drive configurations to be employed, with the engine unit or units operating at near to full load capacity. This would avoid the fuel-expensive, part-load performance, exhibited by gas turbine drive systems, for example, which have hitterto, restricted applicability.

\section{Methods}

In this exercise the dual gas turbine drive system, shown in Figure 1, will be considered. All of the inertias and frictional coefficients for the GT engines are referred to the main drive shaft, as in [3]. The prime mover inertia and combustion dynamic effects can be represented by simple, exponential delays and gain terms, as in [4] and [5]. 


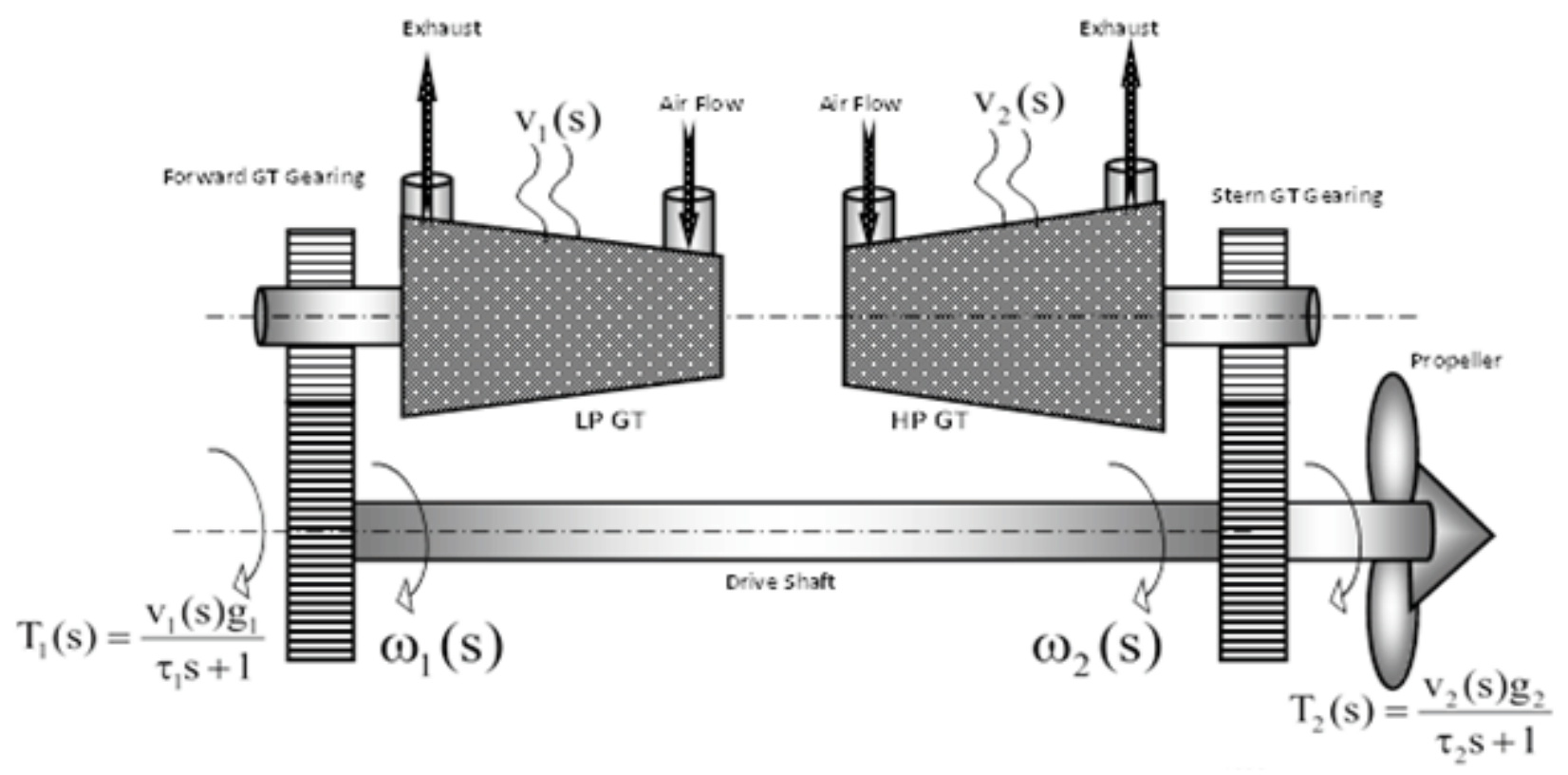

Figure 1. Dual Gas Turbine Propulsion System

Modelling the drive shaft as a distributed parameter element, as shown in [6] with each prime mover, rotational inertia and gearing represented by lumped elements, at each end of the drive shaft, would be appropriate. The Laplace transformed model for this system, with torque inputs $T_{1}(\mathrm{~s})$ and $\mathrm{T}_{2}(\mathrm{~s})$, is:

$$
\left[\begin{array}{c}
\mathrm{T}_{1}(\mathrm{~s}) \\
-\mathrm{T}_{2}(\mathrm{~s})
\end{array}\right]=\left[\begin{array}{cc}
\zeta_{1} \mathrm{w}_{1}(\mathrm{~s})+\gamma_{1}(\mathrm{~s}) & -\zeta_{1}\left(\mathrm{w}_{1}^{2}(\mathrm{~s})-1\right)^{1 / 2} \\
\zeta_{1}\left(\mathrm{w}_{1}^{2}(\mathrm{~s})-1\right)^{1 / 2} & -\zeta_{1} \mathrm{w}_{1}(\mathrm{~s})-\gamma_{2}(\mathrm{~s})
\end{array}\right]\left[\begin{array}{c}
\omega_{1}(\mathrm{~s}) \\
\omega_{2}(\mathrm{~s})
\end{array}\right]
$$

In equation (1):

$$
\gamma_{1}(\mathrm{~s})=\mathrm{J}_{1} \mathrm{~s}+\mathrm{c}_{1}, \gamma_{2}(\mathrm{~s})=\mathrm{J}_{2} \mathrm{~s}+\mathrm{c}_{2}
$$

then since from $[6]$ :

$$
\zeta_{1}=J_{\mathrm{s}} \sqrt{\left(\rho_{1} G_{1}\right)}
$$

Also:

$$
\mathrm{w}_{1}(\mathrm{~s})=\frac{\mathrm{e}^{21_{1} \Gamma_{1}(\mathrm{~s})}+1}{\mathrm{e}^{21_{1} \Gamma_{1}(\mathrm{~s})}-1}
$$

where in equation (2):

$$
\Gamma_{1}(s)=s \sqrt{\rho_{1} / G_{1}} .
$$

Then following the inversion of equation (1):

$$
\left[\begin{array}{c}
\omega_{1}(\mathrm{~s}) \\
\omega_{2}(\mathrm{~s})
\end{array}\right]=\frac{\left[\begin{array}{ll}
\zeta_{1} \mathrm{w}_{1}(\mathrm{~s})+\gamma_{2}(\mathrm{~s}) & \zeta_{1}\left(\mathrm{w}_{1}^{2}(\mathrm{~s})-1\right)^{1 / 2} \\
\zeta_{1}\left(\mathrm{w}_{1}^{2}(\mathrm{~s})-1\right)^{1 / 2} & \zeta_{1} \mathrm{w}_{1}(\mathrm{~s})+\gamma_{1}(\mathrm{~s})
\end{array}\right]}{\Delta(\mathrm{s})}\left[\begin{array}{c}
\mathrm{T}_{1}(\mathrm{~s}) \\
\mathrm{T}_{2}(\mathrm{~s})
\end{array}\right]
$$

where in equation (3):

$$
\Delta(\mathrm{s})=\zeta_{1}\left(\gamma_{1}(\mathrm{~s})+\gamma_{2}(\mathrm{~s})\right) \mathrm{w}_{1}(\mathrm{~s})+\gamma_{1}(\mathrm{~s}) \gamma_{2}(\mathrm{~s})+\zeta_{1}^{2}
$$

and in delay form since:

$$
\mathrm{w}_{1}(\mathrm{~s})=\left(1+\mathrm{e}^{-2 l_{1} \Gamma_{1}(\mathrm{~s})}\right) /\left(1-\mathrm{e}^{-2 l_{1} \Gamma_{1}(\mathrm{~s})}\right)
$$

then:

$$
\left(\mathrm{w}_{1}^{2}(\mathrm{~s})-1\right)^{1 / 2}=2 \mathrm{e}^{-\mathrm{l}_{1} \Gamma_{1}(\mathrm{~s})} /\left(1-\mathrm{e}^{-2 \mathrm{l}_{1} \Gamma_{1}(\mathrm{~s})}\right)
$$

With the inclusion of the GT fuel pump and combustion dynamics, see for example [7], of approximately:

$$
\mathrm{T}_{1}(\mathrm{~s})=\mathrm{g}_{1} \mathrm{v}_{1}(\mathrm{~s}) /\left(\tau_{1} \mathrm{~s}+1\right)
$$

And

$$
\mathrm{T}_{2}(\mathrm{~s})=\mathrm{g}_{2} \mathrm{v}_{2}(\mathrm{~s}) /\left(\tau_{2} \mathrm{~s}+1\right)
$$

the distributed - lumped system model becomes, in terms of percentage input and output changes:

$$
\left[\begin{array}{c}
\omega_{1}(\mathrm{~s}) \\
\omega_{2}(\mathrm{~s})
\end{array}\right] \cong \frac{\left[\begin{array}{ll}
\zeta_{1} \mathrm{w}_{1}(\mathrm{~s})+\gamma_{2}(\mathrm{~s}) & \zeta_{1}\left(\mathrm{w}_{1}^{2}(\mathrm{~s})-1\right)^{1 / 2} \\
\zeta_{1}\left(\mathrm{w}_{1}^{2}(\mathrm{~s})-1\right)^{1 / 2} & \zeta_{1} \mathrm{w}_{1}(\mathrm{~s})+\gamma_{1}(\mathrm{~s})
\end{array}\right]}{\Delta(\mathrm{s})}\left[\begin{array}{cc}
\frac{\mathrm{g}_{1}}{\tau_{1} \mathrm{~s}+1} & 0 \\
0 & \frac{\mathrm{g}_{2}}{\tau_{2} \mathrm{~s}+1}
\end{array}\right]\left[\begin{array}{l}
\mathrm{v}_{1}(\mathrm{~s}) \\
\mathrm{v}_{2}(\mathrm{~s})
\end{array}\right]
$$

Hence:

$$
\left(\omega_{1}(\mathrm{~s}), \omega_{2}(\mathrm{~s})\right)^{\mathrm{T}}=\mathbf{G}_{\mathrm{s}}(\mathrm{s})\left(\mathrm{v}_{1}(\mathrm{~s}), \mathrm{v}_{2}(\mathrm{~s})\right)^{\mathrm{T}}
$$

In this application the prime mover time constants are approximately equal. Hence if:

$$
\tau_{1}=\tau_{2}=\tau=0.05 \mathrm{sec}
$$

and if the power output of the high power unit is approximately twice that of the low power unit then in 
equation (9):

$\mathbf{G}_{\mathrm{s}}(\mathrm{s})=\mathrm{g}_{1}\left[\begin{array}{cc}\zeta_{1} \mathrm{w}_{1}(\mathrm{~s})+\gamma_{2}(\mathrm{~s}) & 2 \zeta_{1}\left(\mathrm{w}_{1}^{2}(\mathrm{~s})-1\right)^{1 / 2} \\ \zeta_{1}\left(\mathrm{w}_{1}^{2}(\mathrm{~s})-1\right)^{1 / 2} & 2 \zeta_{1} \mathrm{w}_{1}(\mathrm{~s})+\gamma_{1}(\mathrm{~s})\end{array}\right] / \Delta(\mathrm{s})(\tau \mathrm{s}+1)$

In order to regulate shaft speed in this application, a control strategy aimed at attaining a cooperative power drive wherein the gas turbines respond in concert, to achieve the demanded outputs required. To do this the outputs to be controlled could be selected as the shaft twist angle $\phi(s)$ and the shaft speed $\omega_{2}(\mathrm{~s})$. A transformation of the system model, given by equation (9), is necessary to achieve this.

Since:

$$
\phi(s)=\left(\omega_{1}(s)-\omega_{2}(s)\right) / s
$$

then:

$$
\left(\phi(s), \omega_{2}(\mathrm{~s})\right)^{\mathrm{T}}=\mathbf{N}(\mathrm{s}) \mathbf{G}_{\mathrm{s}}(\mathrm{s})\left(\mathrm{v}_{1}(\mathrm{~s}), \mathrm{v}_{2}(\mathrm{~s})\right)^{\mathrm{T}}
$$

where in equation (11) for percentage input and output changes:

$$
\mathbf{N}(\mathbf{s})=\left[\begin{array}{cc}
\theta / \mathrm{s} & -\theta / \mathrm{s} \\
0 & 1
\end{array}\right],
$$

where:

$$
\theta=100 / \phi_{\max }(\mathrm{s})
$$

where here the design limit for $\phi_{\max }(\mathrm{s})=0.1 \mathrm{rads}$, and since

$\mathrm{v}_{1 \max }(\mathrm{s})=\mathrm{v}_{2 \max }(\mathrm{s})=100$ volts, and a $1 \%$ voltage change results in a $1 \%$ torque change, in equation (10).

Also, $\quad \omega_{1 \max }(\mathrm{s})=\omega_{2 \max }(\mathrm{s}) \cong 100 \mathrm{rads} / \mathrm{sec}$, with normal operational speed limited to $50 \%$ maximum in this marine propulsion system application. With this transformation the output response from equation (11), following input step changes of $1 \%$, are all over damped with time constants of $1.25 \mathrm{sec}$.

The inner loop control law, for this application, as shown in [8], is:

$$
\left(\mathrm{v}_{1}(\mathrm{~s}), \mathrm{v}_{2}(\mathrm{~s})\right)^{\mathrm{T}}=\mathbf{k}(\mathrm{s})\left(\overline{\mathbf{r}}(\mathrm{s})-\overline{\mathbf{h}}(\mathrm{s})\left(\phi(\mathrm{s}), \omega_{2}(\mathrm{~s})\right)^{\mathrm{T}}\right)
$$

and the block diagram representation is shown in figure 2 .

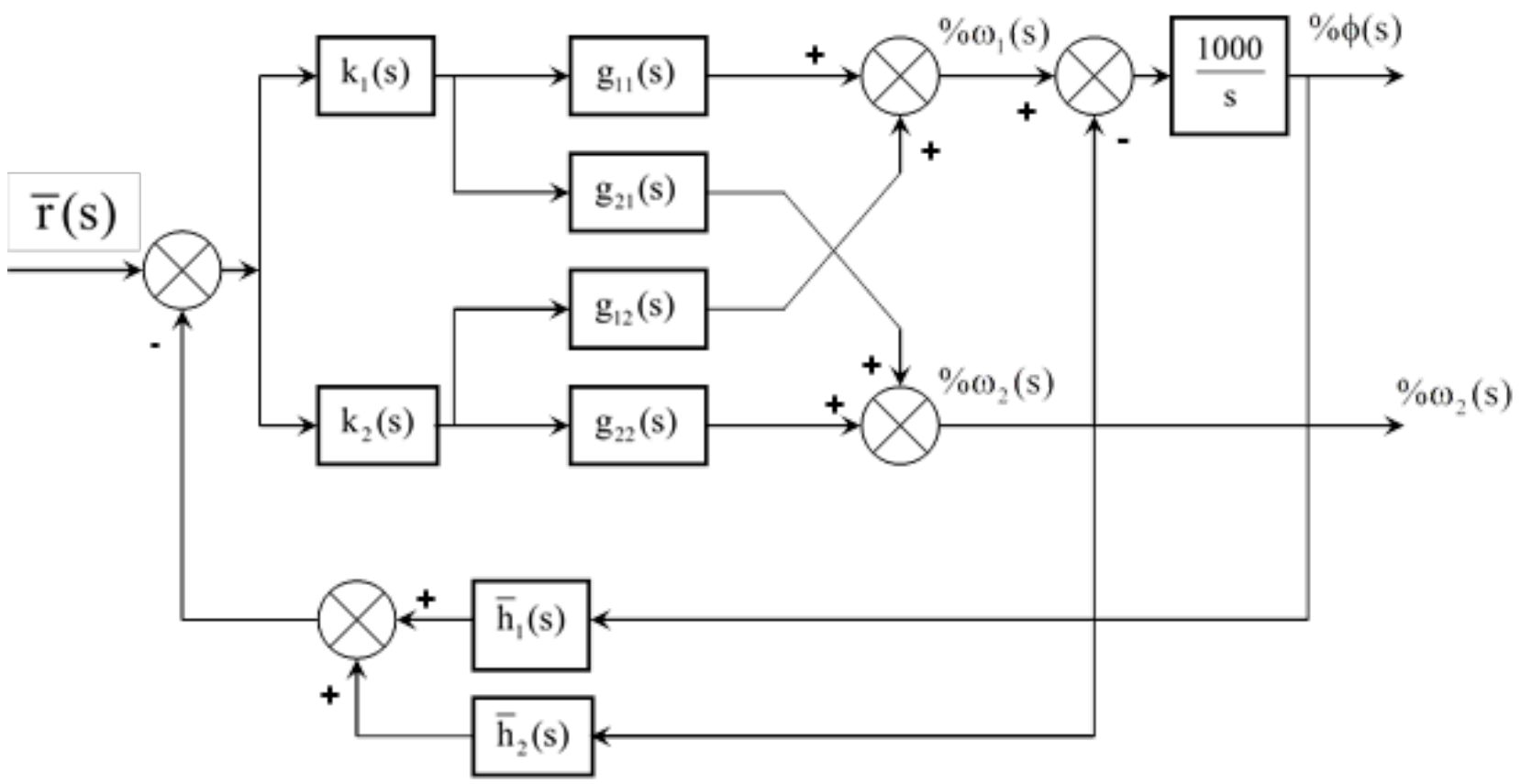

Figure 2. Inner Loop Block Diagram 
Hence:

$$
\begin{aligned}
& \left(\phi(\mathrm{s}), \omega_{2}(\mathrm{~s})\right)^{\mathrm{T}}= \\
& =\left(\mathbf{I}_{2}+\mathbf{N}(\mathrm{s}) \mathbf{G}_{\mathrm{s}}(\mathrm{s}) \mathbf{k}(\mathrm{s})><\overline{\mathbf{h}}(\mathrm{s})\right)^{-1} \mathbf{N}(\mathrm{s}) \mathbf{G}_{\mathrm{s}}(\mathrm{s}) \mathbf{k}(\mathrm{s}) \overline{\mathrm{r}}(\mathrm{s})
\end{aligned}
$$

In equation (13) the determinant required is:

$$
\begin{aligned}
\operatorname{det}\left(\mathbf{I}_{2}+\mathbf{N}(\mathrm{s}) \mathbf{G}_{\mathrm{s}}(\mathrm{s}) \mathbf{k}(\mathrm{s})><\overline{\mathbf{h}}(\mathrm{s})\right)= \\
1+<\frac{\left[10^{3} \mathrm{~h}_{1}(\mathrm{~s}),\left(\mathrm{sh}_{2}(\mathrm{~s})-10^{3} \mathrm{~h}_{1}(\mathrm{~s})\right)\right] \mathbf{G}(\mathrm{s}) \mathbf{k}(\mathrm{s})}{\mathrm{s}}>
\end{aligned}
$$

The inner product, in equation (14), may be written as:

$$
v(s)\left[\boldsymbol{\Phi}(\mathrm{s})\left(\mathrm{k}_{1} \overline{\mathrm{h}}_{1}, \mathrm{k}_{2} \overline{\mathrm{h}}_{1}, \mathrm{k}_{1} \overline{\mathrm{h}}_{2}, \mathrm{k}_{2} \overline{\mathrm{h}}_{2}\right)^{\mathrm{T}}-\mathbf{I}_{3} \lambda\right]=0
$$

where in equation (15):

$$
\begin{aligned}
& \overline{\mathrm{h}}_{1}=10^{3} \mathrm{~h}_{1}(\mathrm{~s}) \text { and } \overline{\mathrm{h}}_{2}=\mathrm{sh}_{2}(\mathrm{~s})-10^{3} \mathrm{~h}_{1}(\mathrm{~s}) \\
& \mathrm{v}(\mathrm{s})=\left[\left(\mathrm{w}_{1}^{2}(\mathrm{~s})-1\right)^{1 / 2}, \mathrm{~s}, 1\right] /(\mathrm{s}(\tau \mathrm{s}+1) \Delta(\mathrm{s})) \\
& \lambda=\left(\lambda_{1}, \lambda_{2}, \lambda_{3}\right)^{\mathrm{T}} \mathrm{g}_{1} \text { is the multiplier for } \mathrm{v}(\mathrm{s}) \text { and: }
\end{aligned}
$$

$$
\Phi(\mathrm{s})=\left[\begin{array}{cccc}
\frac{\zeta_{1}\left(\mathrm{w}_{1}^{2}(\mathrm{~s})-1\right)^{1 / 2}}{\mathrm{w}_{1}(\mathrm{~s})} & 2 \zeta_{1} & \zeta_{1} & \frac{\zeta_{1}\left(\mathrm{w}_{1}^{2}(\mathrm{~s})-1\right)^{1 / 2}}{\mathrm{w}_{1}(\mathrm{~s})} \\
\mathrm{J}_{2} & 0 & 0 & 2 \mathrm{~J}_{1} \\
\mathrm{c}_{2}+\frac{\zeta_{1}}{\mathrm{w}_{1}(\mathrm{~s})} & 0 & 0 & 2\left(\mathrm{c}_{1}+\frac{\zeta_{1}}{\mathrm{w}_{1}(\mathrm{~s})}\right)
\end{array}\right]
$$

Putting: $\mathrm{k}_{2}=\mathrm{nk}_{1}$ and with the low frequency condition that:

$$
\left(\mathrm{w}_{1}^{2}(\mathrm{~s})-1\right)^{1 / 2} / \mathrm{w}_{1}(\mathrm{~s})=1,1 / \mathrm{w}_{1}(\mathrm{~s})=0,
$$

then since $v(s) \neq 0$, in equation (15)

$$
\left[\begin{array}{cc}
\zeta_{1}+2 \mathrm{n} \zeta_{1} & \zeta_{1}+2 \mathrm{n} \zeta_{1} \\
\mathrm{~J}_{2} & 2 \mathrm{~J}_{1} \mathrm{n} \\
\mathrm{c}_{2} & 2 \mathrm{c}_{1} \mathrm{n}
\end{array}\right]\left[\begin{array}{l}
\overline{\mathrm{h}}_{1} \\
\overline{\mathrm{h}}_{2}
\end{array}\right]=\left[\begin{array}{l}
\lambda_{1} \\
\lambda_{2} \\
\lambda_{3}
\end{array}\right] \mathrm{g}_{1}
$$

where in equation (16) the coefficients $\lambda_{1}, \lambda_{2}$ and $\lambda_{3}$ become the weights for the characteristic equation:

$$
1+v(s) \lambda=0
$$

The solution for the first two equations, of equation (16) is:

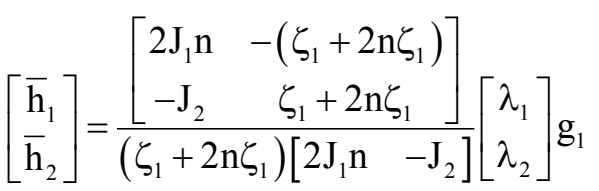

so that since $J_{1}$ and $J_{2}$ are very small, in comparison to $\zeta_{1}$ then:

$$
\left[\begin{array}{c}
10^{3} \mathrm{~h}_{1}(\mathrm{~s}) \\
\mathrm{sh}_{2}(\mathrm{~s})-10^{3} \mathrm{~h}_{1}
\end{array}\right]=\frac{\left[\begin{array}{c}
-\lambda_{1} \\
\lambda_{2}
\end{array}\right] \mathrm{g}_{1}}{\left(2 \mathrm{~J}_{1} \mathrm{n}-\mathrm{J}_{2}\right)}
$$

and $\lambda_{3}$ can be calculated following the establishment of $h_{1}(s)$ and $h_{2}(s)$ to satisfy the third equation, of equations (16). The simplest solution here would be to let: $\lambda_{1}=\lambda_{2}=\lambda$, in equation (19) so that $\operatorname{sh}_{2}(\mathrm{~s})$ would be zero and:

$$
\mathrm{h}_{1}(\mathrm{~s})=\frac{-\lambda \mathrm{g}_{1} 10^{-3}}{\left(2 \mathrm{~J}_{1} \mathrm{n}-\mathrm{J}_{2}\right)}
$$

Although the gain ratio $\mathrm{n}$, in equation (15), may be selected arbitrarily, to achieve the optimum, least effort controller requires the minimisation of the functional:

$$
\mathbf{J}=\boldsymbol{\lambda}^{\mathrm{T}}\left(\mathbf{Q}^{-1}(\mathrm{n})\right)^{\mathrm{T}} \mathbf{Q}^{-1}(\mathrm{n}) \boldsymbol{\lambda}
$$

where in equation 21 :

$$
\lambda=\left(\lambda_{1}, \lambda_{2}, \lambda_{3}\right)^{\mathrm{T}} \mathrm{g}_{1}
$$

and from equation (18):

$$
\mathbf{Q}(\mathrm{n})=\left[\begin{array}{cc}
\zeta_{1}+2 \mathrm{n} \zeta_{1} & \zeta_{1}+2 \mathrm{n} \zeta_{1} \\
\mathrm{~J}_{2} & 2 \mathrm{~J}_{1} \mathrm{n}
\end{array}\right]
$$

Since for a particular application $\mathrm{J}_{1}, \mathrm{~J}_{2}$ and $\zeta_{1}$, and $\mathbf{Q}(\mathrm{n})$, will be known, the minimisation of the $\mathrm{J}$ functional enables the gain ratio $\mathrm{n}$, where $\mathrm{k}_{2}=\mathrm{nk}_{1}$, to be determined from the optimisation process.

Consequently, the relative stability condition for the inner loop can now be assessed from equation (17) which results in:

$$
\frac{\left(\lambda_{1}\left(\mathrm{w}_{1}^{2}(\mathrm{~s})-1\right)^{1 / 2}+\lambda_{2} \mathrm{~s}+\lambda_{3}\right) \mathrm{g}_{1}}{(\mathrm{~s}(\tau \mathrm{s}+1) \Delta(\mathrm{s}))} \neq-1
$$

In the frequency domain, with $s=i \omega$ the function of equation (22) must leave the $-1,0$ point to the left for: $0<\omega<\infty$ since this system is open-loop stable.

\section{Results}

In this illustrative application study a marine propulsion system which has a drive shaft of length $l_{1}$, with polar second moment of area of $J_{s}$, will be considered. The arrangement of the system is as shown in fig. 1, where there are relatively lumped inertias and bearing frictions, referred to the shaft, at the stern and at the forward end. The system parameters are: 
$\mathrm{J}_{1}=6.0 \times 10^{-2} \mathrm{kgm}^{2}, \mathrm{~J}_{\mathrm{s}}(\mathrm{shaft})=0.61359 \times 10^{-6} \mathrm{~m}^{4}$,

$\mathrm{J}_{2}=15.0 \times 10^{-2} \mathrm{kgm}^{2}, \mathrm{c}_{1}=0.5, \mathrm{c}_{2}=20 \mathrm{Nm} \mathrm{sec} / \mathrm{rad}$,

$\mathrm{l}_{1}=4.0 \mathrm{~m}, \mathrm{~d}=0.05 \mathrm{~m}, \mathrm{G}_{1}=80 \times 10^{9} \mathrm{~N} / \mathrm{m}^{2}$,

$\rho_{1}=7800 \mathrm{~kg} / \mathrm{m}^{3}, \mathrm{~m}=2$.

From these values, as shown by equation (2):

$$
\begin{gathered}
\zeta_{1}=J_{s} \sqrt{\left(\rho_{1} G_{1}\right)}=15.3275 \\
\Gamma_{1}(s)=s \sqrt{\left(\rho_{1} / G_{1}\right)}=\left(3.122499 \times 10^{-4}\right) \mathrm{s}
\end{gathered}
$$

The time constant $\tau$ of the prime movers for illustration purposes is:

$$
\tau=0.05, \gamma_{1}(\mathrm{~s})=\mathrm{J}_{1} \mathrm{~s}+\mathrm{c}_{1} \text { and } \gamma_{2}(\mathrm{~s})=\mathrm{J}_{2} \mathrm{~s}+\mathrm{c}_{2}
$$

The first step in the design procedure is to establish the inner, closed loop controller details, as this loop is used to adjust the system dynamics. The calculation for the optimum gain ratio $\mathrm{n}$ can be determined from equation 21 which when evaluate for this system becomes:

$$
\begin{gathered}
J=\lambda^{T}\left(\mathbf{Q}^{-1}(\mathrm{n})\right)^{\mathrm{T}} \mathbf{Q}^{-1}(\mathrm{n}) \boldsymbol{\lambda} \\
\mathrm{J}=\left[\left(1+\mathrm{n}^{2}\right)\left(\lambda \mathrm{g}_{1}\right)^{2} \times 10^{-6}\right] /(12 \mathrm{n}-15)^{2} \times 10^{-4}
\end{gathered}
$$

The graph of function (26) is shown in fig. 3, where, since $\mathrm{g}_{1}$ does not affect the value of $\mathrm{n}$, minimising $\mathrm{J}$, this has been included as unity. Clearly, the minimum value of $\mathrm{J}$ occurs when:

$$
\mathrm{n}=-0.8
$$

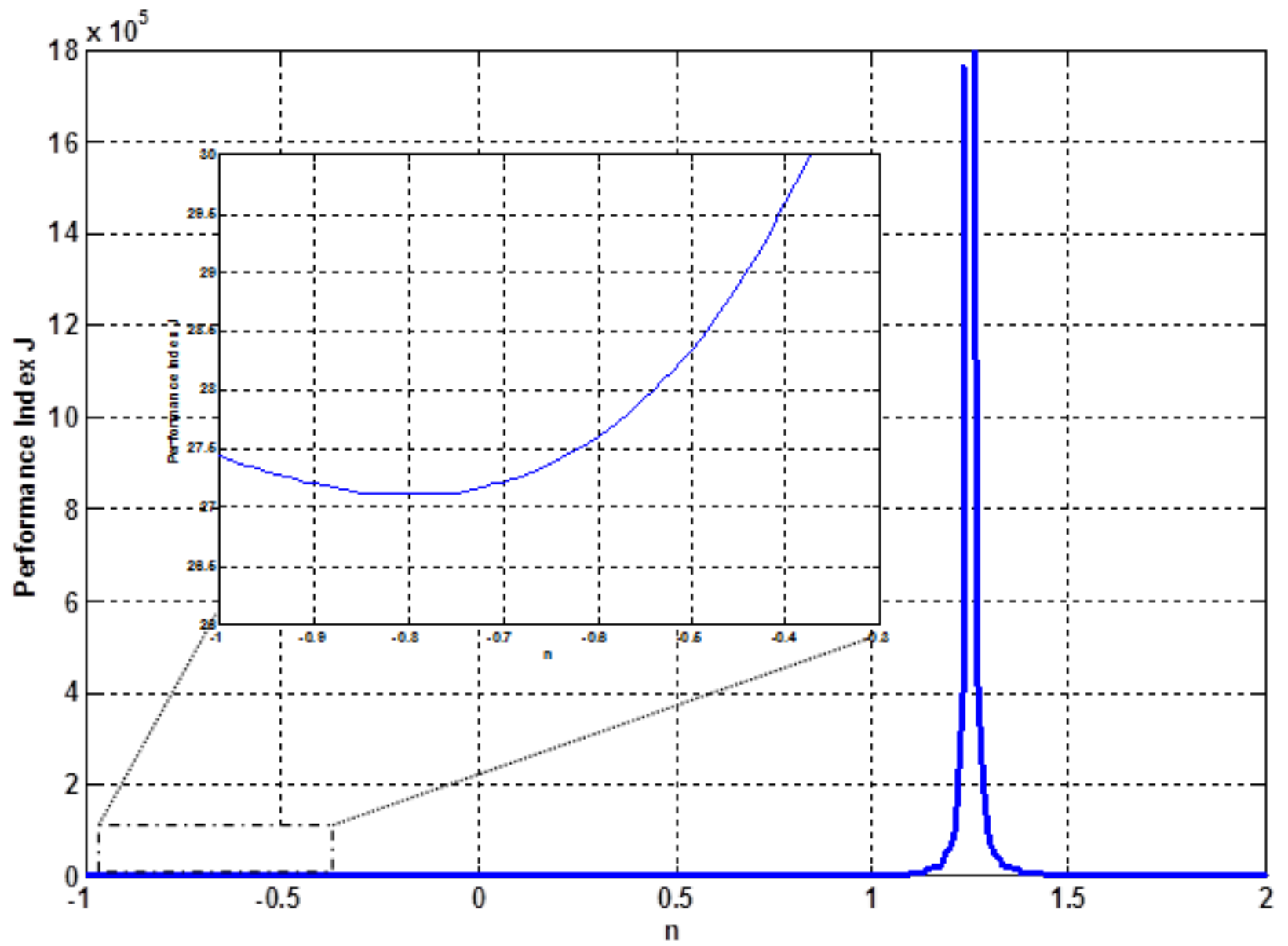

Figure 3. Performance Index J against $n$ 


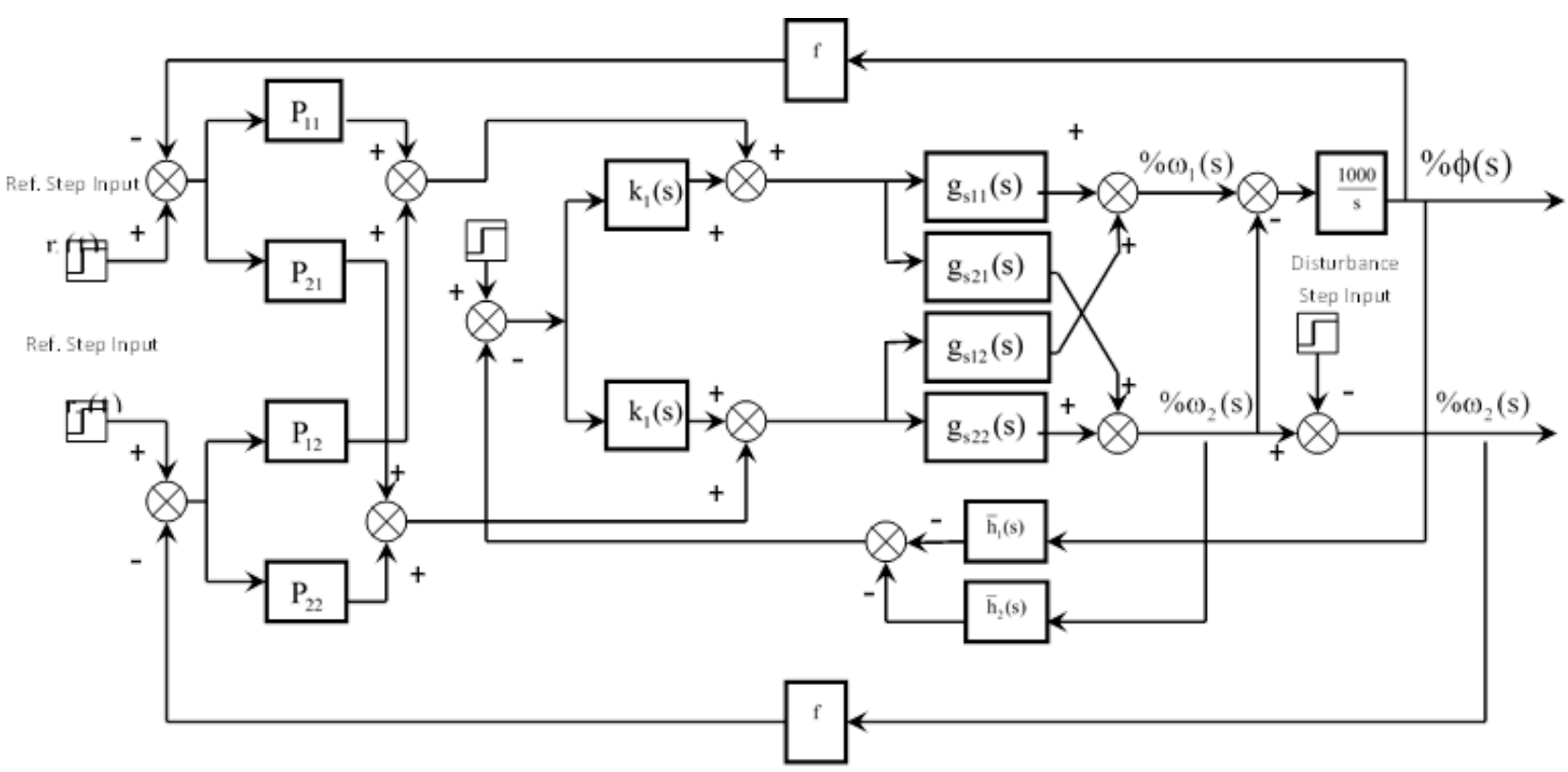

Figure 4. Closed Loop Configuration for Analysis

With this value of $\mathrm{n}$ and following the substitution of $\mathrm{J}_{1}, \mathrm{~J}_{2}, \mathrm{c}_{1}$ and $\mathrm{c}_{2}$, with the selection of: $\lambda=\lambda_{1}=\lambda_{2}$, to simplify the inner-loop feedback, equation (18) results in:

$$
\begin{aligned}
& \lambda_{3} \mathrm{~g}_{1}=\mathrm{c}_{2} \overline{\mathrm{h}}_{1}+2 \mathrm{c}_{1} \mathrm{n} \overline{\mathrm{h}}_{2} \\
& \lambda_{3}=4.06 \lambda
\end{aligned}
$$

Hence, the $v(s) \lambda$ function of equation 17 is:

$$
v(s) \lambda=\frac{\lambda g_{1}\left(\left(w_{1}^{2}(s)-1\right)^{1 / 2}+s+3.0 \overline{3}\right)}{(s(\tau s+1) \Delta(s))}
$$

where $\Delta(\mathrm{s})$ is given by equation (3).

A Nyquist diagram for equation (28) with conservative gain and phase margins, acknowledging thereby the inclusion of the finite time delays and for:

$\lambda \mathrm{g}_{1}=1000$ could be drawn.

From equation (19), since:

$$
\begin{aligned}
& \mathrm{h}_{2}=0 \text { and } \mathrm{h}_{1}=4.06, \text { with } \mathrm{n}=-0.8, \text { and with } \\
& \mathrm{k}_{1}=1 \text {, and } \mathrm{k}_{2}=-0.8
\end{aligned}
$$

this fully defines the feedback concluding the inner-loop design.

To complete the outer-loop design the pre-compensator $\mathbf{P}$ must be computed. Since:

$$
\mathbf{G}(0)=\left.\mathbf{N}(\mathrm{s}) \mathbf{G}_{\mathrm{s}}(\mathrm{s})\right|_{\mathrm{s} \rightarrow 0}
$$

and with an initial selection of a steady state matrix to allow $0.1 \%$ steady state output coupling:

$$
\mathbf{S}_{\mathrm{s}}=\left[\begin{array}{cc}
1 & 0.1 \\
0.1 & 1
\end{array}\right]
$$

then since:

$$
\mathbf{k}=(1,-0.8)^{\mathrm{T}}, \mathbf{h}=(4.06,0)
$$

The pre compensator can be derived as shown in [8], as:

$$
\mathbf{P}=\left[\left(\left.\mathbf{N}(\mathrm{s}) \mathbf{G}(\mathrm{s})\right|_{\mathrm{s} \rightarrow 0}+\mathbf{k}(0)><\mathbf{h}(0)\right) \mathbf{S}_{\mathrm{s}}\left(\mathbf{I}_{2}-\mathbf{F S}_{\mathrm{s}}\right)\right]
$$

Several values of: $\mathbf{F}=\mathrm{fI}_{2}, 0<\mathrm{f}<1$ may be employed.

Using L'Hopital's theorem (see for example [9]), evaluation yields:

$$
\left.\mathbf{N}(\mathrm{s}) \mathbf{G}(\mathrm{s})\right|_{\mathrm{s} \rightarrow 0}=\left[\begin{array}{cc}
0.0794 & -0.0038 \\
0.0488 & 0.0975
\end{array}\right]
$$

so that for $\mathrm{f}=0.7$, for example:

$$
\mathbf{P}=\left[\begin{array}{cc}
54.7365 & 1.6288 \\
-31.5193 & 33.3727
\end{array}\right],
$$

Figure 4 shows the final closed-loop configuration for analysis purposes. For implementation purposes, a conventional pre and feedback compensator structure may now be determined. Hence,

$$
\mathbf{K}(\mathrm{s})=\mathbf{P} \text { and for } \mathrm{f}=0.7
$$

$$
\mathbf{H}(\mathbf{s})=\left[\mathbf{P}^{-1}\left[\begin{array}{c}
1 \\
-0.8
\end{array}\right]\left[\begin{array}{ll}
4.06 & 0
\end{array}\right]+0.7 \mathbf{I}_{2}\right]=\left[\begin{array}{cc}
0.7763 & 0 \\
-0.027 & 0.7
\end{array}\right]
$$

To demonstrate effectiveness the performance of the closed-loop system following a reference input step change on the speed demand $r_{2}(t)$ will be investigated, for three values of outer loop gain, $f=0.7,0.8$ and 0.9 . Thereafter, for the same values of outer-loop gain the disturbance suppression and recovery characteristics of the system will be determined, with the imposition of step disturbances on 
the shaft angular velocity output $\omega_{2}(t)$.

In fig. 5 and 6 the response of the system following reference input, step changes on $r_{2}(t)$ are shown. Fig. 5 exhibits well behaved, monotonic transients with the speed of response improving, for increasing values of outer loop feedback gain, $f$. The distributed parameter shaft dynamics are shown in figure 6 where the oscillatory, shaft twist angle characteristics increase substantially, as f increases, with rising energy transmission and hence shaft torsional, transient excitation.

In figs. 7 and 8 the fuel flow change to the forward and stern GT engines, respectively, are shown following a step demand on $r_{2}(t)$. Here, the stern end GT is shown to support the major part of the load change with the forward end GT, containing the shaft twist angle by executing the high frequency oscillations depicted in figure 7 , allowing the smooth power transition, illustrated by figure 5 .

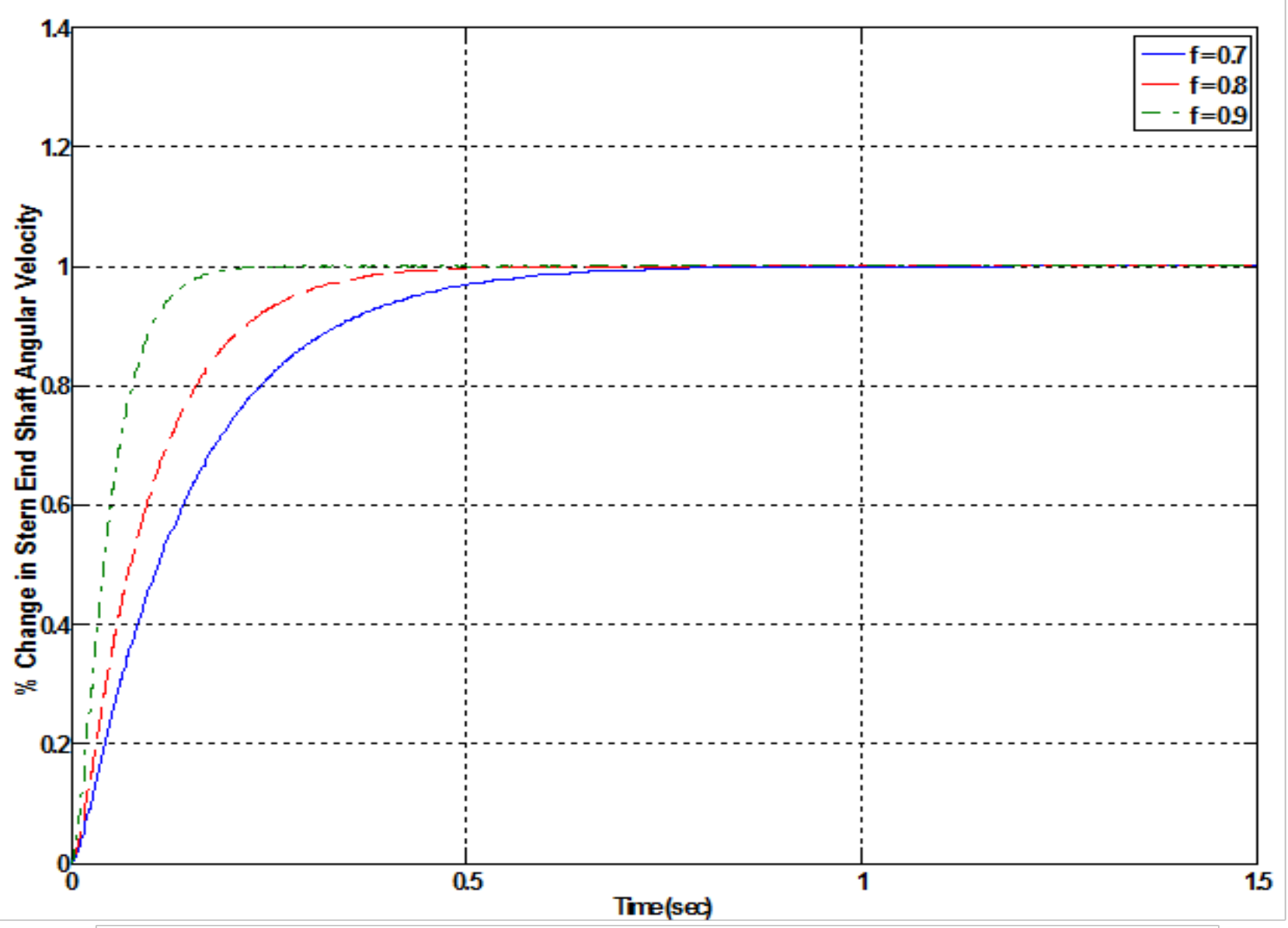

Figure 5. \% Change in Shaft Angular Velocity Following a 1\% Step Input Reference Change on $r_{2}(t)$ 


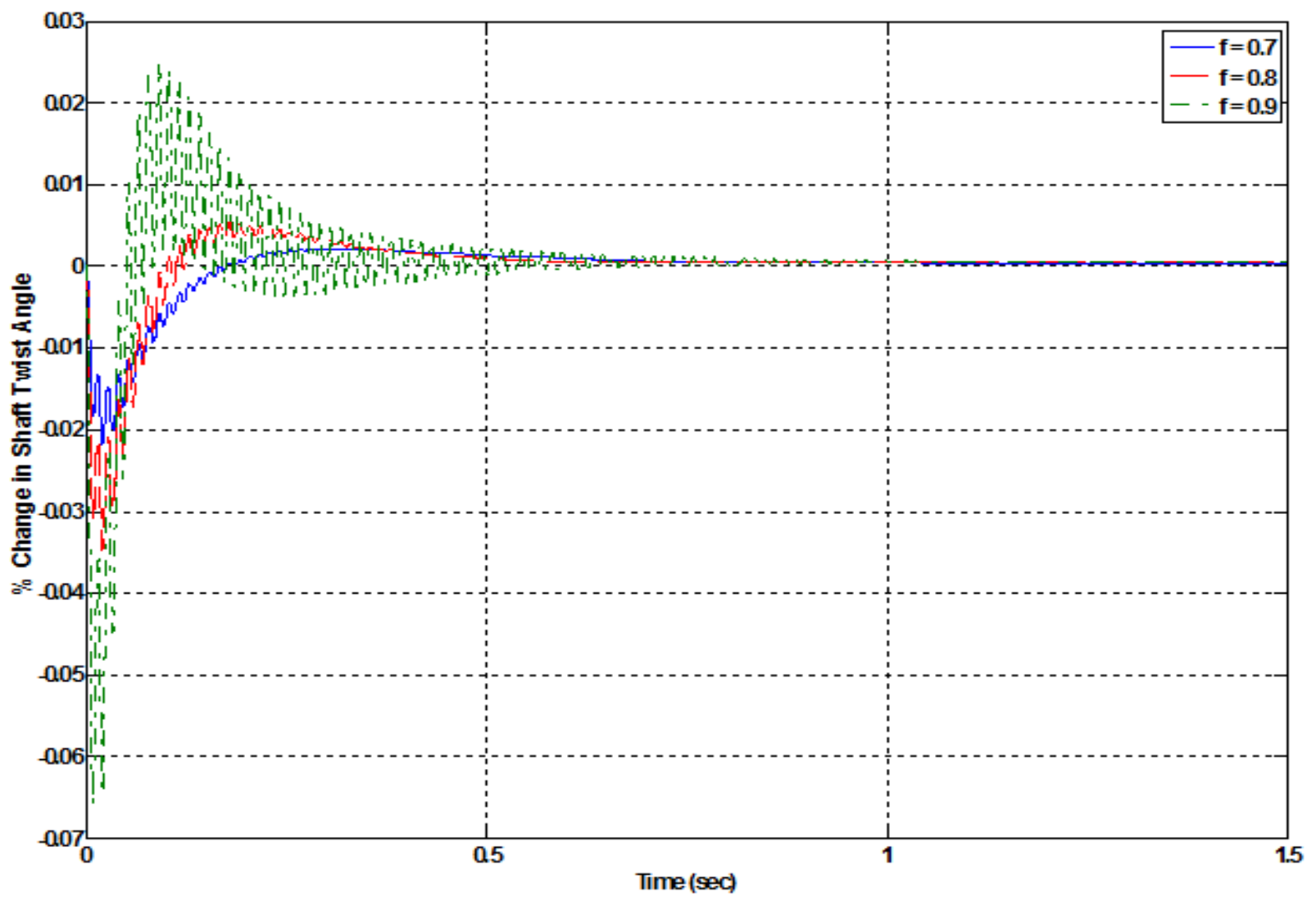

Figure 6. \% Change in Shaft Twist Angle Following a 1\% Step Input Reference Change on $r_{2}(t)$

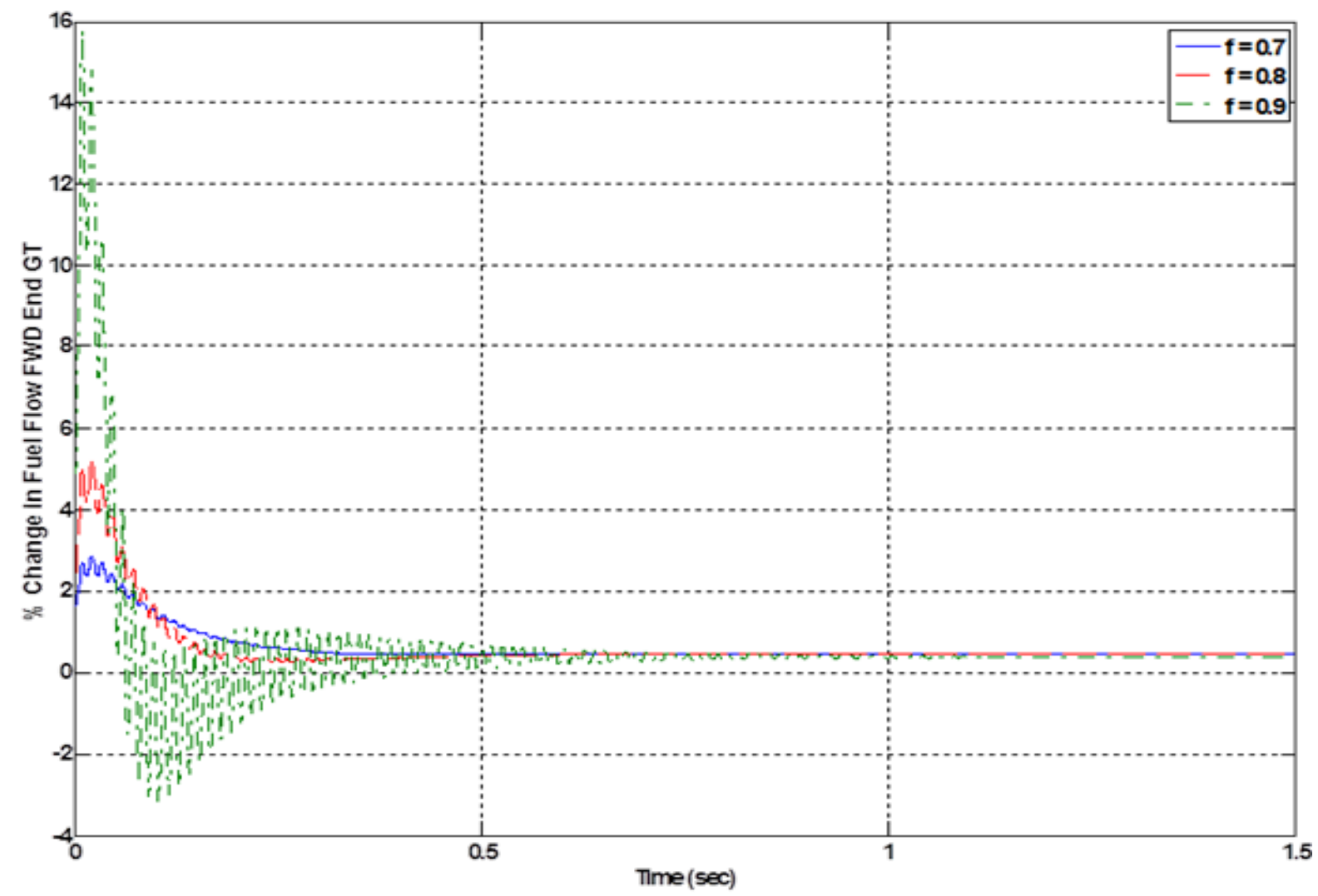

Figure 7. \% Change in Fud Flow to Fwd End GT Following a 1\% Step Input Reference Change on $\mathrm{r}_{2}(\mathrm{t})$ 


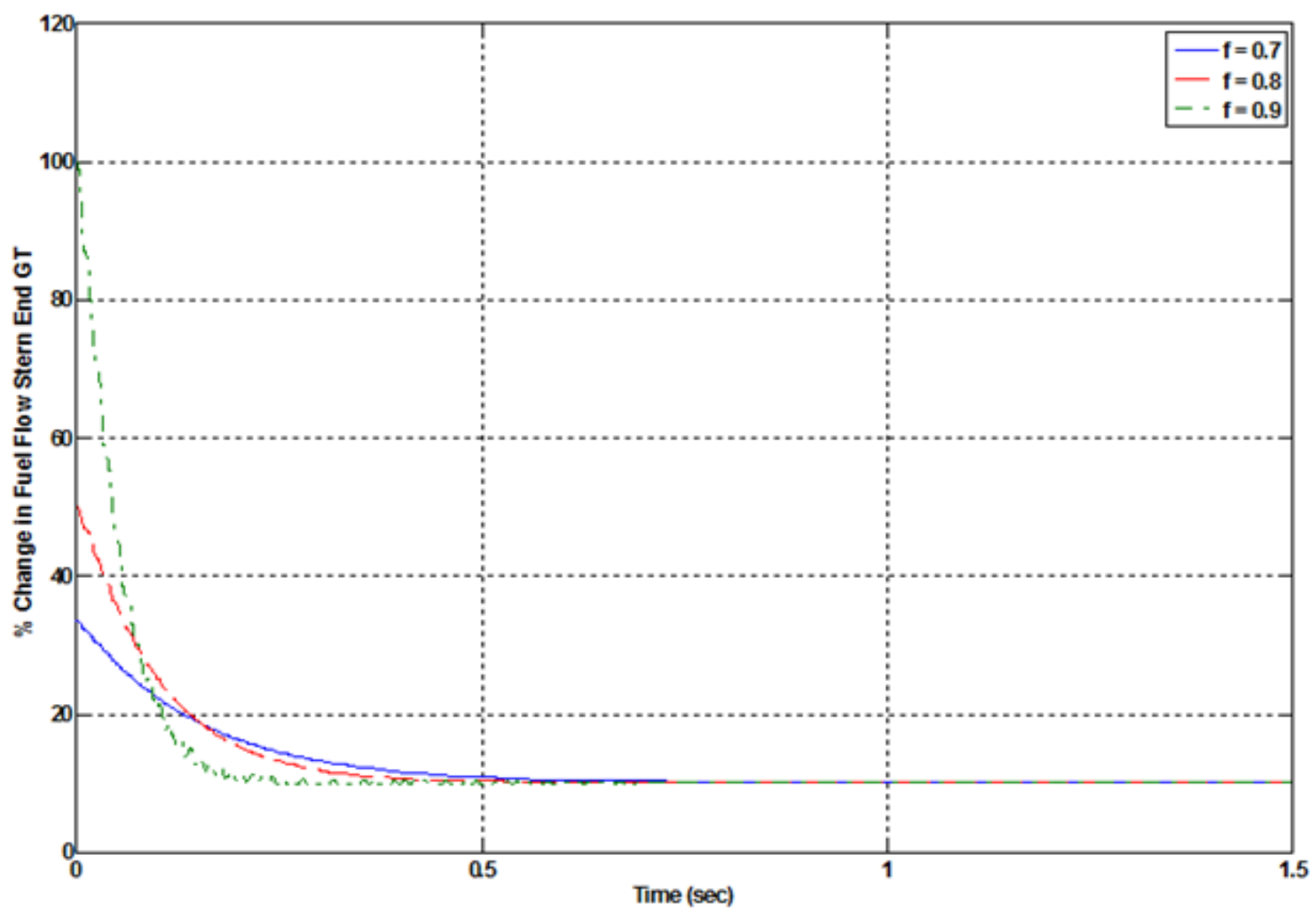

Figure 8. \% Change in Fud Flow to Stern End GT Following a 1\% Step Input Reference Change on $r_{2}(t)$

The disturbance suppression performance of the system is also pleasing, as shown in fig. 9 where the system off-set is reduce with increasing values of outer-loop gain f. Fig. 10 indicates that the shaft twist angle change reduces to zero within approximately 0.5 seconds with a similar build-up of oscillatory behaviour, to that exhibited following reference input signal changes.

To counter load changes, fig. 11 shows that there is a permanent increase in fuel flow to the forward end GT.

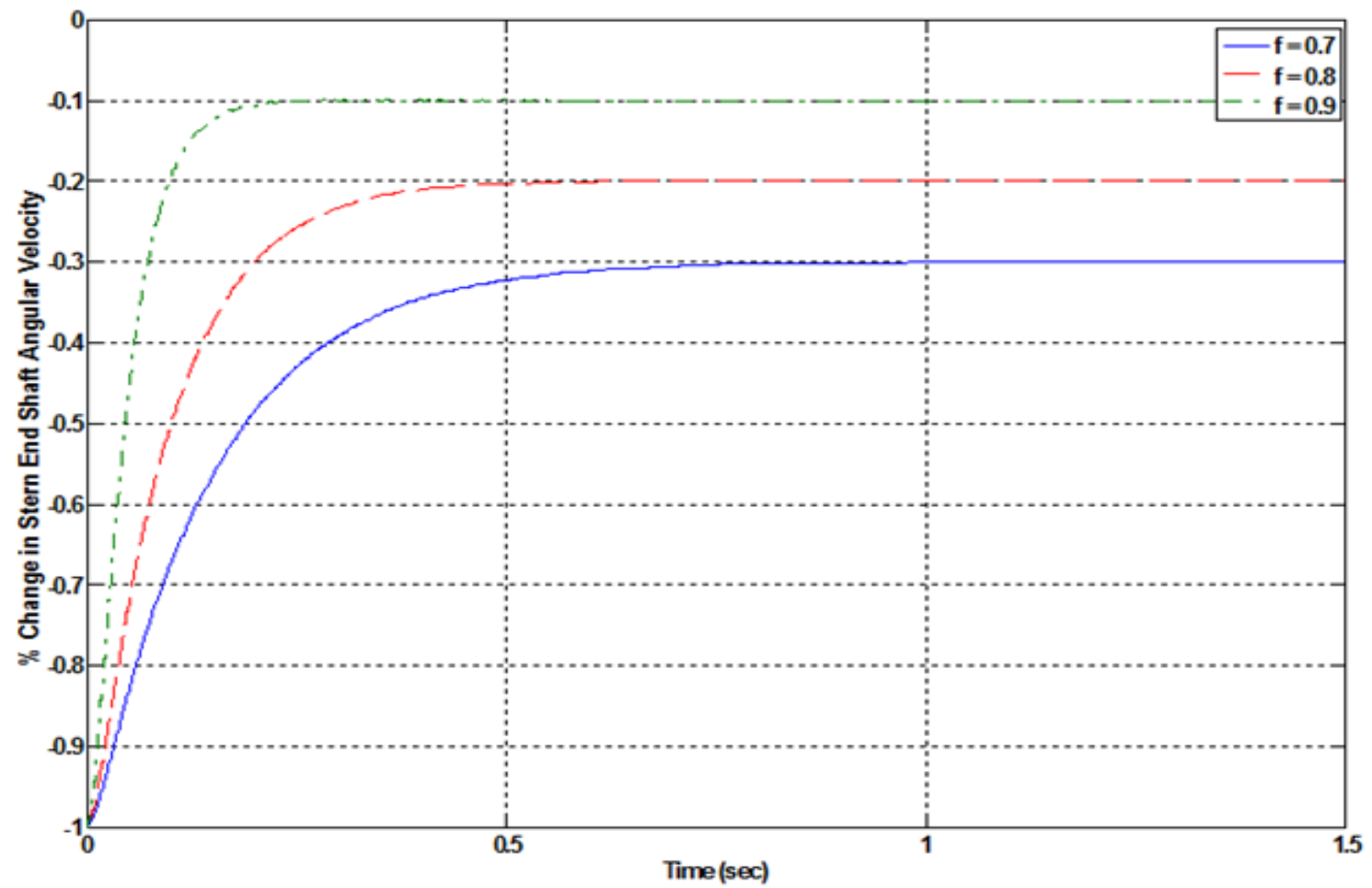

Figure 9. \% Change in Shaft Angular Velocity Following a 1\% Step Disturbance Change on Shaft Velocity $\omega_{2}(t)$ 


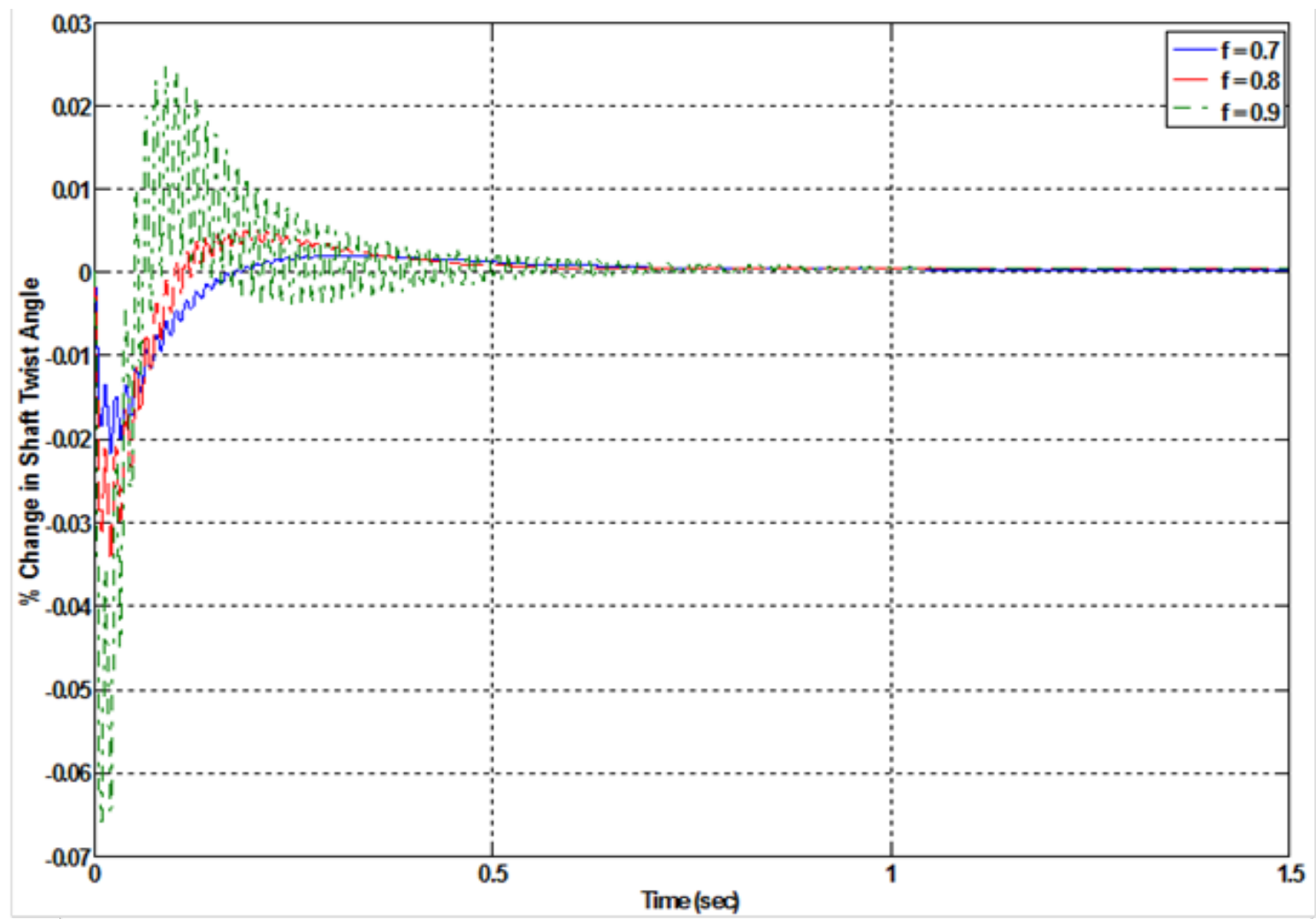

Figure 10. \% Change in Shaft Twist Angle Following a 1\% Step Disturbance Change on Shaft Velocity $\omega_{2}(\mathrm{t})$

Equally, figure 12 shows a permanent increase in fuel flow to the stern end GT without the rapid transient excitation which the smaller, forward end GT exhibits.

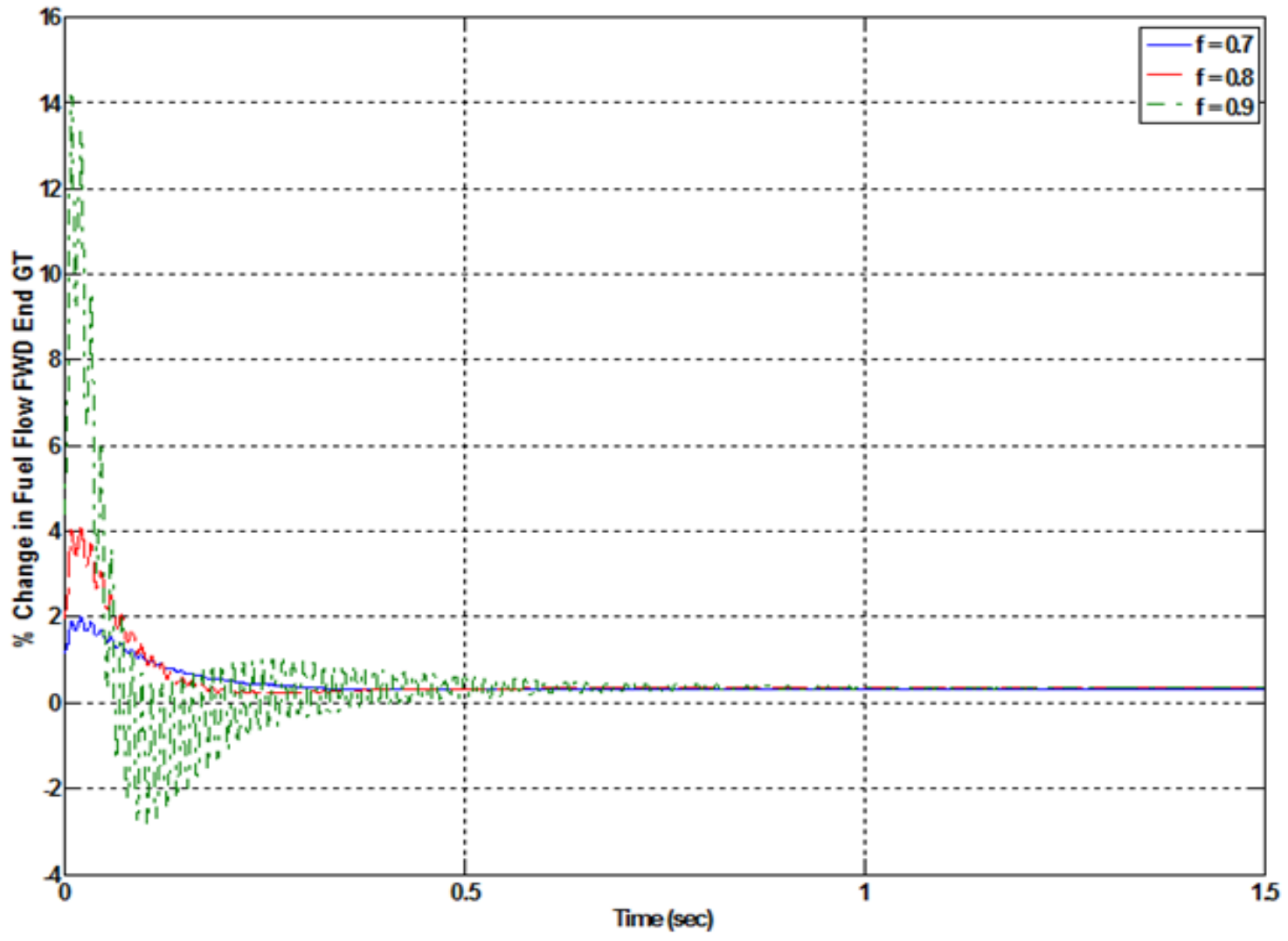

Figure 11. \% Change in Fuel Flow to Fwd End GT Following a 1\% Step Disturbance Change on Shaft Velocity $\omega_{2}(t)$ 


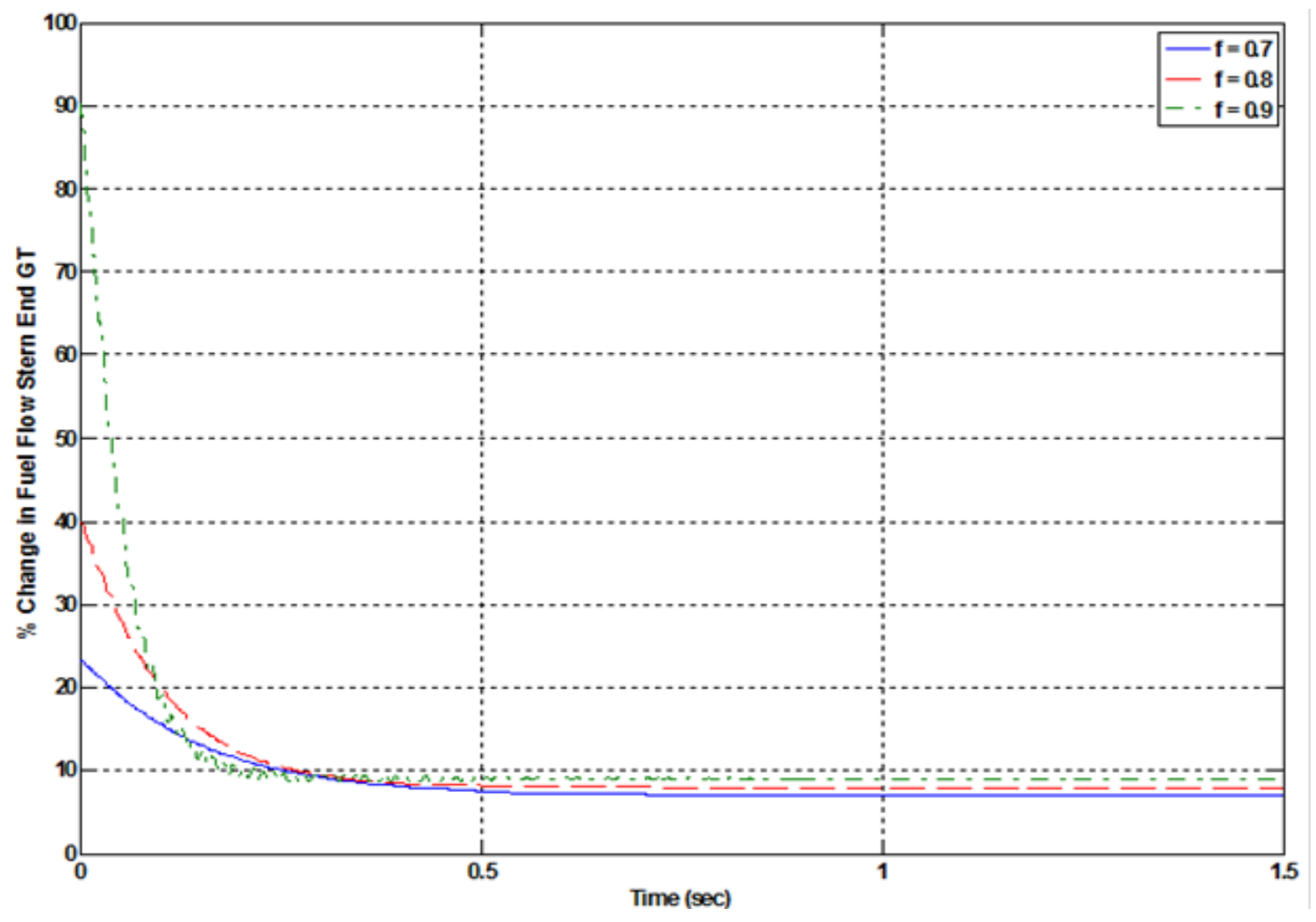

Figure 12. \% Change in Fuel Flow to Stern End GT Following a 1\% Step Disturbance Change on Shaft Velocity $\omega_{2}(t)$

\section{Conclusions}

The difficulty in operating with tandem drives is that imbalance often occurs with one prime mover "motoring" on the drive shaft. For this reason, separate low and high power systems are usually used. In particular, in warship applications the high power system is usually provided by large capacity gas turbine units, driving the port and starboard shafts, respectively, whilst the smaller cruise drive may employ engines of less than $50 \%$ of this capacity.

As, shown herein, the initial analysis reflects the complexity of the situation with the system input-output matrix model exhibiting numerical singularity at low frequencies and with extremely small model determinant values at all frequencies.

This arises from the rigidity of the shaft model and from the elementary observation that the steady state running speed, at each end of the shaft, is identical. To overcome this design difficulty a transformation was proposed enabling the basic model to be used to compute shaft twist, as well as the stern end shaft speed. This system shaft speed and twist angle, matrix model is well posed (regular) enabling the prediction of steady state conditions in the design/analysis exercise.

In particular, the requirement for both speed and twist angle control could now be accommodated within the inner and outer loop design structure employed, for least effort regulation. The inputs could also be coupled if desired, so that a demanded speed change would automatically allow a prescribed increase in the steady state shaft twist angle, in accordance with normal running conditions.

Following the least effort design procedure, the computed response predictions for step input changes, on the shaft speed, reference input, were shown to illustrate effectiveness. The regulated response of the system, as shown from the transients, improves without exciting non-minimum phase transients, overshoot or settling time problems.

Finally, the focus of the study was mainly concerned with the desirability of employing a tandem drive, rather than separate low and high power propulsion units. As shown herein, this is achievable providing accurate modelling and an efficient feedback regulation strategy is imposed.

This gives the clearly identifiable advantages demonstrated. These include improvements in steady state and dynamic performance, operating efficiency, reduced maintenance cost all of which are important in marine operations.

\section{Acknowledgements}

The author wishes to acknowledge the support and encouragement for this research provided by the Vice Chancellor, The British University in Dubai-UAE.

\section{REFERENCES}


[1] D. K. Dutton, S. Thompson and R. Baraclough, "The Art of Control Engineering”, Addison Wesley. Harlow, 1997.

[2] H. Bartlett and R. Whalley, Proc. IMechE, pt. C, Vol. 212, 1998, pp. 497-508.

[3] R. V. Patel and N. Munro, "Multivariable System Theory and Design", International Series on Systems and Control, Vol. 4, Pergamon Press, Oxford, 1984.

[4] R. Whalley and M. Ebrahimi, "Automotive Gas Turbine Regulation", IEEE Trans. Control System Tech., Vol. 12, no. 4, 2004, pp.465-473

[5] R. Whalley and M. Ebrahimi, "Gas Turbine Propulsion Plant Control”, ASNE, Nav. Eng. Journal, Vol. 114, no. 4, 2002, pp.77-94.

[6] R. Schwartz and B. Fredland, "Linear Systems", McGraw-Hill, N.Y., 1965.

[7] D. E. Winterbone, N. Munro and P. M. G. Lountie, "Design of a Multivariable Controller for an Automotive Gas Turbine", ASME Gas Turbine Conference, Washington, 1973.

[8] R. Whalley and M. Ebrahimi, "Multivariable System Regulation", Proc. IMechE, pt. C, Vol. 220, 2006, pp. 653-666.

[9] B. Bradie, "Numerical Analysis", Pearson Int. Inc., New Jersey, 2006. 